\title{
MATT FERRANTO
}

\section{$\Gamma\rfloor$}

\author{
Autocriação digital no \\ ciberespaço: o novo \\ autorretrato digital \\ Tradução: Daniela Kern
}

RESUMO

O presente artigo aborda, através da análise dos fenômenos da Internet Peter Oakley e Little Loca, as novas possibilidades de autorretrato, de criação da própria imagem pública nos meios virtuais disponíveis na contemporaneidade, delineando ainda uma contextualização histórica relevante para a compreensão do autorretrato e de sua posição no universo virtual disponibilizado pela Internet.

PALAVRAS-CHAVE

Autorretrato digital. Internet. Autocriação. 


\section{AUTOCRIAÇÃO DIGITAL NO CIBERESPAÇO: O NOVO AUTORRETRATO DIGITAL}

Publicação original: FERRANTO, Matt. Digital Self-Fashioning in Cyberspace: The New Digital Self-Portrait. In: KROMM, Jane; BAKEWELL, Susan Benforado.A history of visual culture: western civilization from the 18th to the 21 st century. Oxford; New York: Berg, 2010. p. 356-366.

MARGOLIS, Jonathan. 'Geriatric' Peter, the global web star. Saga Magazine, march 15, 2007. Disponivel em: <http://www.saga. co.uk/magazine/people/reallives/ geriatric|927_|60307.asp>.

2

HELLER, Stephen. The new generation gap: an exploratory conversation with John Carlin. Voice: The AIGA Journal of Design, may 22, 2007. Disponivel em: <http://www.aiga.org/content.chm/ the-new-generation-gap $>$.
Uma das maiores sensações de mídia de 2006 não foi um rapper ou um videogame, mas um recluso viúvo de setenta e nove anos, do distrito britânico de Peak District, que queria "contar tudo".Vestindo um cardigã de golaV e sentado calmamente diante de um papel de parede com padrões florais, Peter Oakley focou uma câmera de vídeo em si mesmo e contou histórias do ataque aéreo da Luftwaffe, em 1942, seu amor de toda a vida por motocicletas, sua experiência hesitante com a tecnologia computacional contemporânea e uma variedade do que ele chamou de "resmungos e queixas geriátricos". Depois de postar seus vídeos no YouTube sob o apelido de geriatric 1927, Oakley atraiu mais de meio milhão de espectadores em menos de um mês; seus vídeos estavam entre as mais populares atrações do site, obtendo milhares de comentários de espectadores e dezenas de vídeos criados em resposta. Enquanto se autocriava como um "avô universal",' que abertamente confessava seu vício em vídeos do YouTube na web, Oakley permanecia um indivíduo dolorosamente tímido. Quando repórteres e outras pessoas começaram, inevitavelmente, a procurar por ele em pessoa, ele desviava do assunto, anunciando, em seus vídeos, que vivia em uma cidade a cinquenta milhas de distância e que dirigia uma motocicleta.

Quem era esse geriatric 1927? Juntamente com essa facilidade de comunicação, a era digital promete novos formatos de autoexpressão e, consequentemente, estratégias de autocriação. Fotografia digital e vídeo, associados à distribuição online, são concepções que expandem tanto o eu quanto sua representação. De fato, para a emergente "geração @”, espaços virtuais e redes eletrônicas tornaram-se centros sociais, enquanto as imagens digitais são pontos cruciais de autodefinição. ${ }^{2} \mathrm{O}$ advento do ciberespaço habilitou um crescente número de sites para o intercâmbio de ideias e opiniões, e muitas dessas opções expandiram as oportunidades para a autoexpressão tanto como para a autopromoção. Ele proporcionou um novo fórum para o autorretrato, mas também facilitou uma crescente visualização da identidade. Com o acesso a esses sites aberto e garantido, mesmo os mais experimentais formatos de autoapresentação e retrato têm a capacidade de comunicar em uma vasta escala. O autorretrato digital, ligado em rede, inevitavelmente requer uma investigação da forma através da história. Os estudiosos tradicionalmente situaram o advento do 
autorretrato visual com a adoção, pelos humanistas, do sentido de self durante o Renascimento europeu. À parte retratos sub-reptícios, incluindo marginália de monges em manuscritos medievais, concorda-se, em geral, que os primeiros autorretratos visuais autônomos nos quais o artista é a figura central emergiram no final do século $\mathrm{XV}$. Algumas dessas pinturas parecem ter funcionado como propaganda do ofício do pintor, tais como o Autorretrato em um espelho convexo, de Parmigianino, de cerca de I524. Mas, cada vez mais, eles também podem ser vistos como afirmações do self; de Van Gogh a Picasso, a vanguarda tomou a autorrepresentação como principal ferramenta autoexpressiva através dos séculos XIX e $X X$. Ainda que se possam apresentar argumentos de que alguma arte popular ou outsider abarca autorretratos, o autorretrato permanece em grande parte sob a alçada de artistas profissionais durante o começo do século $X X$.

Enquanto o crescimento da fotografia entre artistas não identificados pode indicar um consequente crescimento do autorretrato, a digitalização levou ao florescimento do autorretrato amador. Um boom menor na fotografia ocorreu no século $X X$, quando as classes médias, com a novidade do tempo de lazer, apoderouse da fotografia em grande número. Mas, mesmo então, fotógrafos não profissionais treinavam suas lentes em amigos, animais de estimação, familiares, eventos ou paisagens com muito maior frequência do que em si mesmos. Americans in Kodachrome, 1945-65 (2002) inclui instantâneos selecionados de quinhentas famílias americanas; o autor Guy Stricherz revisou mais de cem mil imagens ao longo de dezessete anos ao compilar o livro, mas encontrou menos de cem autorretratos. ${ }^{3}$ De acordo com Stricherz, "em 1960, uma pessoa simplesmente não iria tirar uma fotografia Kodak Brownie de si mesma. Isso seria considerado demasiado autoengrandecedor". 4 Tão recentemente como vinte anos atrás, as fotografias eram geralmente usadas para documentar ocasiões especiais. As fotografias custam dinheiro e tempo de revelação, as cópias e os negativos tomam espaço em caixas ou gavetas e são difíceis de mostrar a qualquer um além de um círculo fechado de amigos. Hoje, não apenas as imagens fotográficas são fáceis de manipular e estocar, mas os autorretratos digitais em homepages se tornaram cruciais para a ideia de comunidade virtual e para uma audiência cada vez mais ampla e inclusiva.

A digitalização, em oposição à própria fotografia, levou ao florescimento do autorretrato amador. Aclamadas como "arte popular para a era digital", ${ }^{5}$ tais imagens resultam do advento das câmeras digitais baratas, leves, junto com armazenamento digital e manipulação de imagens; o efeito verdadeiramente democratizador da distribuição on-line tornou ubíquo o autorretrato visual. Novas tecnologias em vídeo e em fotografia fazem mais do que usar dados binários para capturar e registrar imagens. Há uma alquimia aqui que convida o amador. Nos anos 1970, mesmo filmes fotográficos pré-embalados, baratos e simples, que os usuários tinham de colocar
3 WILLIAMS, Alex. Here I am taking my own picture. The New York Times, february 19, 2006, section 9. p. I.

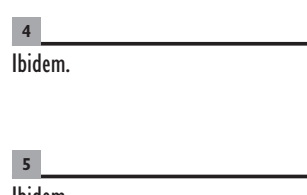

Ibidem. 
JACKSON, Michele H.; PURCELL, Darren. Politics and media richness in World Wide Web representations of the former Yugoslavia. Geographical Review, 87, n. 2, p. 219, april 1997. em câmeras do tipo "apontar e fotografar", ainda eram geralmente processados por profissionais em slides ou cópias em papel a partir de negativos. Modelos Polaroid relativamente volumosos criavam fotos em papel únicas no espaço de cinco minutos ou algo assim. Mas tais imagens eram difíceis de editar e distribuir. Imagens digitais, em contraste, são facilmente estocadas; imagens indesejadas são meramente deletadas da própria câmera. Outras imagens podem ser editadas em um computador pessoal. Os modelos de câmeras são extremamente pequenos ou portáteis, e os dispositivos fotográficos são frequentemente encontrados acoplados a telefones celulares ou mesmo a chaveiros. Mesmo câmeras digitais em telefones celulares frequentemente vêm equipadas com lentes grande-angulares; imagens tomadas na extensão do braço podem ainda permanecer com foco.Técnicas sofisticadas de edição e retoque, antes disponíveis apenas para profissionais ou amadores praticantes com acesso a câmaras escuras de milhares de dólares, agora podem ser obtidas com o clique de uns poucos botões em programas de computador como o Photoshop. Além do mais, com os computadores domésticos ficando cada vez mais rápidos e poderosos, as telas antes dedicadas ao processamento de textos são cada vez mais usadas para ver e processar fotos pessoais e filmes. Prescindindo do uso de estúdios profissionais, e mesmo da ajuda de amigos e da família, os indivíduos agora criam retratos como um ato solitário.

Mas tal ato de retratar não é necessariamente isolador; o rápido desenvolvimento da Internet proporcionou aos fotógrafos digitais uma audiência disponível. Gerações anteriores não eram capazes de distribuir suas fotos, enquanto os autorretratos digitais podem ser vistos por milhões na web. Sites como YouTube e Flickr permitem a Peter Oakley e milhões de outros compartilhar com o mundo as imagens que criam de si mesmos.

Enquanto tais sites de compartilhamento de fotos exibem um notável espectro de imagens de numerosos estilos visuais distintos, a Internet era originalmente o que um observador chamou de "um mundo de palavras, não de imagens". ${ }^{6}$ Desenvolvida no final dos anos 1960 como um projeto do Departamento de Defesa dos Estados Unidos, a web foi formulada como um sistema de hipertexto global, no qual os usuários podem acessar vários documentos de texto; HyperText Markup Language, ou HTML, a linguagem codificadora usada para criar documentos em hipertexto para aWorldWide Web, não era inicialmente configurada para exibir gráficos. Mesmo nos anos 1980 , quando companhias privadas, universidades e laboratórios de pesquisa se combinaram para criar uma rede de servidores de computador, interruptores e roteadores que ampliaram a Internet e terminaram com o domínio militar na rede de computadores, suas transmissões eram limitadas a texto. Rapidamente, no entanto, os engenheiros de software de vários stripes introduziram novas tags HTML que iriam controlar a aparência de um documento, em vez de especificar a organização do documento. Mosaic (1993), de Marc Andreessen e Eric Bina, foi o primeiro browser multiplataforma 
a ganhar ampla popularidade, introduzindo suporte para som, videoclipes, suporte a formulários, bookmarks e arquivos de histórico, e rapidamente se tornou o mais popular browser não comercial da web. ${ }^{7}$ Mas os comentadores observam que tais browsers permitiam orações, manifestos e diatribes, assim como discursos de ocasião ou salons, mas não "pôsteres, flyers, ou atualidades". ${ }^{8}$ O elemento adicional do visual, junto com a facilidade e a liberdade de movimento eletrônico possibilitadas pelo hipertexto, transformou o que era um recurso obscuro disponível para engenheiros e tecnocratas na agitada corrente principal da cultura popular e do comércio global. Acima de tudo, a web se tornou um instrumento para apresentação, abrindo uma gama de possibilidades, primeiro para milhares e mesmo milhões de pessoas, para a criação da personalidade e da identidade.

Quando, no começo dos anos 1990, o vice-presidente Al Gore ajudou a popularizar a noção da revolução digital como uma "superhighway da informação", dificilmente ele poderia esperar que isso também fosse uma nova rota para moldar a identidade. ${ }^{9}$ Mesmo antes que a web se transformasse em um meio visual, os indivíduos frequentemente criaram personas na cultura on-line; em trocas de e-mail, salas de bate-papo ou jogos com múltiplos jogadores, o autorretrato baseado em texto rapidamente se desenvolveu. Em seu nível mais complexo, os mundos virtuais em tempo real para múltiplos jogadores, ou MUDS (Multi-User-Dungeons), permitiram aos jogadores criar, manter e destacar esses selfs textuais, usando pseudônimos como descrições de personas. Esse estágio relativamente inicial da tecnologia da web estabeleceu o e-mail e as salas de bate-papo como sites em que o contato e a troca podem ser mantidos e destacados de acordo com o desejo do usuário, e quase imediatamente retratos baseados em texto surgiram, enquanto a subjetividade se tornou uma construção mais ficcional. ${ }^{10}$

Ainda que a Internet inicial permitisse autocriação textual limitada, a confluência da imagística digital e uma audiência disponível da web mudaram essa situação na metade dos anos 1990. Desde os primeiros dias da web, homepages pessoais proporcionaram algumas das mais prevalentes formas de autorrepresentação digital. Um dos primeiros desses foi Howard Rheingold, que em 1995 tinha uma página que apresentava um "pixel theatre" de suas pinturas, incluindo uma na porta de sua estufa, que ele finalizou pintando apenas em seu aniversário a cada ano, por cinco anos; um diário de suas viagens (com imagens e indicadores para homepages de pessoas interessantes que ele visitou) e outras coisas. Concebidas por pesquisadores britânicos em 1993, de modo que seu grupo disperso pudesse se manter informado sobre a quantidade de café em sua única cafeteira, as webcams foram rapidamente manufaturadas e propagandeadas como o brinquedo tecnológico que é preciso ter. Mas a primeira webcam rapidamente se transformou em algo mais; o agora famoso Trojan Room Coffee Pot Web inadvertidamente ecoou o brando descomprometimento
STEWART, Bill. Web browser history: mosaic. Living Internet, 1996-99. Disponivel em: <http://www.livinginternet.com/w/wi_browse.html>.

JACKSON; PURCELL, 1997, p. 219.

GORE, Albert. Remarks. The superhighway summit, UCLA Royce Hall, january II, 1994. Disponivel em: < http:// clintonI.nara.gov/White_House/EOP/ OVP/other/superhig.html>.

10

AVGITIDOU, Angeliki. Performances of the Self. Digital Creativity, I4, n. 3, p. I35-36, 2003. 
11

WALLACK, Todd. Curtains in the bedroom - JenniCam switches Off. San Francisco Chronicle, december 12, 2003, B4.

12

BLOOD, Rebecca (Ed.). We've got blog: how weblogs are changing our culture. New York: Perseus Group Book, 2002. do Empire de Andy Warhol e também obteve um similar status de cult, granjeando mais de dois milhões de visitas à página e gerando cobertura mundial da mídia. Mais tarde, sites pessoais com frequência estavam conectados a web câmeras, que agem como o ego observador do autor, ou no extremo mais distante, como uma exposição exibicionista. Muitos sites webcam consideram o amadorismo como uma posição criativa provocativa e persuasiva, na medida em que assumem a premissa telejornalística da visão próxima, pessoal até limites imprevistos. Um dos primeiros e mais populares sites webcams pessoais foi Jennicam (1996), de Jenifer Kaye Ringley. Depois de instalar uma webcam em seu dormitório no Dickinson College, ela eventualmente cobrava pela observação de sua vida quotidiana, que, como um observador de mídia notou, podia incluir "sentar diante de seu PC em topless, passear pelo quarto vestindo nada além de uma toalha na cabeça ou mesmo rolando sobre os lençóis com seu namorado"." Ringley mais tarde apareceu como uma convidada em um talk show de televisão e foi apresentada em exposições de museu.

Não diferentemente das fantasias infantis de ancorar o próprio show de televisão, muitos sites oferecem um novo tipo de empreendimento autobiográfico em uma extensão nunca antes imaginada. Talvez a mais vibrante arena de discurso, os web logs, ou blogs, passou a ser tratada como ocasiões pós-modernas de autocriação. Uma publicação frequente e cronológica de comentários e pensamentos na web, os blogs usualmente incluem links para histórias, press releases e (frequentemente) outras entradas de blog às quais o escritor está respondendo; eles tipicamente são atualizados todos os dias, usando softwares que permitem aos indivíduos com pouco ou nenhum background técnico atualizar e manter o blog. Blogs oferecem possibilidades expressivas e narrativas e cada vez mais usam imagens do blogger ou links para imagens que visualmente realçam e organizam o texto. Emergindo das listas de links para outros websites - entre os primeiros blogs amplamente reconhecidos estava 0 Justin's links from underground, de Justin Hall, que ele começou como um estudante no Swarthmore College, em 1994, e o Scripting news, de Dave Winer, de 1997 - os sites agora frequentemente combinam textos e imagens com um componente interativo; leitores muitas vezes postam comentários e retratos que se tornam uma importante parte de muitos blogs. ${ }^{2}$ Esses sites tendem a compartilhar um conjunto de elementos visuais consistentes, incluindo uma ampla coluna de breves entradas de texto introduzidas por títulos curtos, coloridos, e um texto menor indicando a data e a hora da postagem, e uma coluna mais estreita listando blogs e outros sites que o blogger implícita ou explicitamente recomenda. Amparados pela mesma premissa dos blogs baseados em texto são os sites de compartilhamento de fotos como o Flickr, nos quais as pessoas podem postar, organizar, procurar e arquivar fotos digitais. Tais sites diretos, no entanto, facilitavam mais do que a comunicação; eles transformaram a natureza da autorrepresentação. 
Os comentadores agora observam que "a arte do autorretrato nunca foi tão popular". ${ }^{3}$ Os autorretratos digitais tirados com câmeras e telefones celulares alimentam tais desenvolvimentos. Mas a transformação da Internet em um meio visual, acoplado com a flexibilidade do hipertexto, mudou a natureza do autorretrato.Visuais e autoelucidativos, homepages, blogs baseados em texto, webcams ou conjuntos de fotos podem todos ser considerados autorretratos expandidos; representando novas formas não imaginadas pelos autorretratistas no Renascimento, os autorretratos digitais se infiltram na web. Frequentemente encontrados nas homepages dos usuários, eles complementam e muitas vezes suplantam os perfis em texto com entradas do tipo blog, detalhando opiniões pessoais, realizações ou eventos. Acima de tudo, autorretratos digitais, tanto fixos como em vídeo, modelam a autoapresentação.

Previamente, o que os psicólogos chamam de "administração da impressão" era ditado pela roupa, por como se ri ou sorri, pela inflexão de voz e coisas assim. ${ }^{14}$ Traduzindo para o ciberespaço, os usuários apresentam a si mesmos através de deixas alternativas. Alguns podem ser textuais, incluindo entradas do tipo diário ou linhas de poesia. Mas muitos autorretratos incorporados tirados com câmeras digitais ou mesmo videoclipes caseiros, enquanto outros incluem mais imagística alusiva, constituindo um autorretrato compósito. Exibindo os conteúdos de um closet ou de uma bolsa, alguns podem ser mais metafóricos; essas imagens com frequência servem como exercícios de gosto e discernimento, algo assemelhados à exibição de uma coleção pessoal de livros ou obras de arte. Novas formas de autorretrato baseado na web incluem diários em vídeo ou memórias como as reminiscências de Oakley. Outros sites são preenchidos com fotografias de refeições de usuários ou imagens de locais visitados por um autor durante o dia. Nesse contexto, então, o autorretrato digital deve se tornar um tipo de arte popular; mas é também um tipo de plataforma para a autocriação.

Em Renaissance self-fashioning, Steven Greenblatt argumenta que "a mais simples observação que podemos fazer é a de que no século XVI parece haver um crescimento na autoconsciência sobre o estabelecimento da identidade humana como um engenhoso processo manipulável". ${ }^{15}$ Detectando largamente o fenômeno nos escritos de figuras como Thomas More e Shakespeare e outros escritores associados com a corte de Henry VIII, Greenblatt descreve a autocriação como a criação de si mesmo de acordo com um conjunto de padrões socialmente aceitáveis: "a realização de... uma personalidade distintiva, um modo característico de se dirigir ao mundo, um modo consistente de perceber e de se comportar". ${ }^{16}$ A autocriação pode assumir muitas formas - vestimenta, voz, e assim por diante; nas artes visuais, a autocriação comumente se refere a poses, posturas, adereços e outros elementos de retratos, incluindo autorretratos. Greenblatt sugere que tais "retratos" públicos prometem autonomia e liberdade, mas também estão necessariamente mesclados
13

BRUCKMAN, Amy. Cyberspace is not Disneyland: the role of the artist in a networked world. Getty Art History Information Program, 1995. Disponivel em: <http://www.cc.gatech.edu/ fac/Amy.Bruckman/papers/getty/ disneyland.html>.

14

Para mais informações, cf. GILBERT, Daniel T.; FISKE, Susan T.; LINDZEY, Gardner. The handbook of social psychology. New York: Oxford University Press, 1998.

15 GREENBLATT, Stephen. Renaissance self-fashioning. Chicago: University of Chicago press, 1980. p. 2.

16 GREENBLATT, 1980. 


\section{7}

Para mais sobre isso, cf. MARSDEN, Joanna Woods. Renaissance selfportraiture: the visual construction of identity and the social status of the artist. Yale University Press, 1998.

18

SELF-STYLING after the "end of art": an interview with Richard Shusterman. Parachute, 105, p. 56-63, spring, 2002.

19

Para mais informações, ver TURKLE, Sherry. Life on the screen: identity in the age of the Internet. Simon \& Schuester, 1995 [1985].

\section{0}

BRUCKMAN, 1995

\section{1}

GARRETT, Jesse James. MySpace: design anarchy that works. Business Week Online, january 3, 2006. Avaible at: < http://www.businessweek.com/innovate/content/dec2005/ id20051230_570094.html>. com respostas a autoridade e controle. $\mathrm{Na}$ medida em que os pintores tentaram elevar seu papel social de habilidosos artesãos para poetas visuais, por exemplo, o autorretrato também serviu como um poderoso instrumento promocional. Os artistas frequentemente pintavam a si mesmos como heróis clássicos, como fez Rafael em sua Disputa, ou como cavaleiros imperiais, a exemplo de Las meninas, de Velázquez. Ainda que ele empreenda uma extensiva leitura de Os embaixadores, a maior parte da análise de Greenblatt é baseada nas cartas, nas narrativas pessoais, nas biografias iniciais e nas obras literárias de seus escritores. Aquela imagística visual, especialmente os autorretratos, que podia ser importante na sociedade do Renascimento como um meio de introduzir ideiais culturais e reforçar o lugar dos indivíduos na sociedade, é explorada por outro estudioso ${ }^{17}$ através de noções como a de que a autocriação pode ocorrer em termos contemporâneos nos autorretratos de Cindy Sherman, Vito Acconci e nas obras iniciais de Chris Burden. ${ }^{18}$

Permitindo a qualquer usuário apresentar informações a outros, com poucos intermediários ou censores, a web possibilita aos amadores criar personas e proporciona uma audiência tanto para recebê-las como para responder a elas. Tal autocriação começou antes que as imagens fossem incorporadas à web; e-mail, salas de bate-papo e MUDs introduziram um elemento performativo para a autorrepresentação digital. ${ }^{19}$ Agora abrangendo uma dimensão visual, o autorretrato digital que se vê hoje na web pode aumentar as oportunidades para a autocriação, quer em videoblogs, quer em conjuntos de fotos do tipo diário. Mas essa não é a autocriação de SirThomas More. Ainda que os dispositivos disponíveis para os autorretratistas da web sejam tecnologicamente complexos, os resultados são desiguais; como sugeriu um observador, o ciberespaço não é a Disneylândia. Não é um lugar refinado perfeito, construído por designers profissionais para que o público obedientemente espere na fila a fim de experimentar de modo passivo. Isso "é mais como uma festa de pintura a dedo, e da maior parte dos trabalhos apenas um pai iria gostar". ${ }^{20}$ Acompanhando homepages na rede social MySpace, outro comentador propõe que essa aparência não refinada "manda outra mensagem aos usuários: Somos como vocês. Você não é um designer, nem nós somos". A recusa estudada do "bom design" em modelos de páginas e esquemas de cor, associada à habilidade dos usuários em customizar suas páginas com cores, fontes, músicas, imagens e videoclipes, "se harmoniza com o desejo de autoexpressão da audiência". ${ }^{21}$

O self visual tal como apresentado na web é conscientemente construído e manipulado. $\mathrm{O}$ amadorismo é inerente, dada a relativamente ampla disponibilidade do software de computador que replica processos e efeitos do estúdio fotográfico.Típicos autorretratos do MySpace usam alto contraste em preto e branco ou esquema de cores invertidas; ângulos intensos ou close-ups acrescentam drama. De modo similar, quando Peter Oakley voltou uma câmera para si mesmo e se tornou o "geriatric 
1927", os espectadores viram um homem idoso portando pesados fones de ouvido que olhava para o chão com tanta frequência quanto para seu público enquanto falava; deliberadamente ou não, ele apresentou uma persona amadora, facilmente passando para o personagem de um tímido "avô universal".

Reminiscências de homens idosos como Oakley são recursos literários familiares e seus pensamentos podem ser dispensados como mero bate-papo, mas eles podem com frequência ser tratados como fonte de sabedoria e como muito pertinentes. $\mathrm{Na}$ web, o último é cada vez mais comum, na medida em que Oakley e outras figuras se tornaram como que arquétipos. Além disso, graças aos programas de redes sociais, essa audiência se torna parte da performance na web. Os vídeos de Oakley são acessíveis em sua página doYouTube, mas sua página também apresenta seus "amigos", fãs que postam comentários e seus próprios autorretratos no site, "assinantes" que regularmente olham seus vídeos, e "favoritos", outros sites no YouTube que Oakley recomenda aos espectadores. Assim, o retrato na web se torna mais do que uma única imagem ou vídeo; sites como o de Oakley compreendem tanto imagens do proprietário individual como uma gama de pequenos retratos thumbnail submetidos por indivíduos em sua rede pessoal. Peter Oakley, em seu chalé isolado no norte da Inglaterra, é definido não apenas por seu videodiário, mas também por uma rede visual de amigos e conexões espalhadas pelo globo.

Em 1984, William Gibson identificou o ciberespaço como uma forma de alucinação consensual; ${ }^{22}$ mais recentemente, os críticos da web argumentaram que as "amizades" ilustradas nessas páginas, com frequência formadas entre pessoas que nunca realmente se encontraram, são ilusórias. Mas tal pensamento é equivocado. Em vez de replicar o mundo "real", elas representam um novo modo de pensar e construir a identidade social; como aponta um observador,"[são formados] diferentes tipos de conexões entre pessoas do que aqueles estabelecidos no espaço físico". ${ }^{23}$ YouTube, Myspace, Flickr expõem novos padrões de ligação; mas seu verdadeiro poder está em seu uso das imagens, como o trabalho do artista americano Ethan Ham, que emprega muitas formas distintas de mídias, incluindo o YouTube, demonstra.

No final do século XIX,Vincent Van Gogh pintou a si mesmo contra um fundo de xilogravuras japonesas, sugerindo suas fontes artísticas e inspiração e fazendo uma complexa afirmação sobre si mesmo e sobre o seu lugar no meio artístico da França do final do século XIX. Os autorretratos nos sites das redes sociais podem sugerir formas igualmente alusivas e complexas de criação da própria imagem. Usando uma página modelo básica, os sites de redes sociais como MySpace habilitam, e mesmo encorajam, os indivíduos e exibem uma coleção sempre variável de amigos. Com porções de cada webpage dedicadas a imagens submetidas por membros da rede do proprietário, os sites eram pesados devido às imagens (com textos subsidiários). Enquanto a interação social no espaço físico é amarrada por "deixas de contexto

22 GIBSON, William. Neuromancer. Ace Books, 1984. p. 51.

23 HELLER, 2007. 


\section{4}

WILLIAMS, 2006. p. 12.

\section{5}

FOUCAULT, Michel. What is an author? In: BOUCHARD, Donald F. (Ed.). Language, counter-memory, practice: selected essays and interviews. Ithaca, NY: Cornell University Press, 1977. p. 51. social", a web apresenta uma nova arena de descoberta e exibição; aqui as imagens - especialmente autorretratos digitais - são manipuladas para replicar essas deixas. Nuances de palavras faladas, linguagem corporal e tom emocional são apresentados através de cor, composição e pose. Mas personalidade, status, e conexões são também apresentados através de contatos. Como os cartões de Pokemon ou as bonecas de papel, retratos de amigos compõem mais do que uma coleção. Eles se desviam da tentativa autoconsciente de Van Gogh de citar suas fontes artísticas; eles formam um retrato de ligação em grupo.

Mas as redes na web sempre são mutáveis e cambiantes; amigos podem ser adicionados, descartados e trocados, e o retrato compósito pode mudar. Além disso, autorretratos autônomos tomados com um telefone celular ou uma câmera digital podem ser rapidamente carregados, copiados e descartados, permitindo aos usuários mudar sua autoapresentação com flexível facilidade. $O$ que começou como uma série de pequenas reportagens que esboçavam as reclamações de Oakley com relação ao mundo moderno se aprofundaram à medida que ele carregava vídeos adicionais. Com o tempo, seu blog se tornou mais complexo, emergindo como uma narrativa pessoal que revelava sua "afortunada" seleção para educação depois da idade de quatorze, suas memórias do tempo de Guerra como mecânico de radar, seus anos como um oficial do departamento de saúde, e seu amor por pintura e motocicletas. Outros simplesmente mudam os autorretratos da homepage tão rapidamente como a vestimenta; extravagantes e inteiramente descartáveis, eles adicionam novas imagens para mostrar uma mudança no corte de cabelo, roupas recém-compradas, ou nova maquiagem. ${ }^{24}$

No Retrato de Dorian Gray, de OscarWilde, o protagonista dissoluto trai, mente e provoca suicídios, mas permanece intocado pela passagem do tempo; ao invés disso, seu retrato constantemente muda, ficando cada vez mais monstruoso com cada ato imoral, envelhecendo na medida em que os anos passam. $O$ retrato cambiante de Wilde se torna uma metáfora da decadência. Mas os sempre-cambiantes autorretratos na web podem ser interpretados de modo diferente; teóricos pós-modernos como Jacques Lacan lançam dúvidas sobre o self como um todo inviolável, enfatizando, ao invés disso, a instabilidade e a fragmentação. Além do mais, a própria ideia de autoria, ou representação, foi questionada por filósofos recentes desde Foucault, associando "a questão do autor" a um "momento privilegiado de desindividualização". ${ }^{25}$ Como a artista Cindy Sherman, cujos autorretratos fotográficos trocam e mudam a identidade da funcionária de loja à ingénue e à femme fatale, nós não mais abordamos o self como uma essência única, indivisível.

Tais conceitos habilmente descrevem o âmbito digital. Os autorretratos digitais são fixados na pintura, na pedra ou no texto impresso. Quando Parmigianino pintou seu autorretrato, em I524, ele orgulhosamente retratou a si mesmo como 
um artista bem-sucedido. Ainda que ele possa alterar a pintura, meios tradicionais como a pintura permanecem estáticos. A imagística eletrônica sempre cambiável, no entanto, sugere um self mutável, moldável e pós-moderno. ${ }^{26} \mathrm{O}$ hipertexto, com suas narrativas cambiantes e o potencial para a colaboração interativa, capturou as imaginações dos teóricos mais recentes. ${ }^{27}$ Sua habilidade de abarcar múltiplas narrativas, e a liberdade dos usuários para interagir com ou mesmo mudar as obras de arte, palpavelmente demonstra tais teorias. Mas é a mutabilidade do digital, sua sempre cambiante impermanência, que melhor ecoa as ideias da instabilidade pósmoderna. Sempre mudando, o self digital é compreendido como um conglomerado de múltiplas identidades.

Enquanto a tentativa de autorretrato de Oakley foi relativamente direta, Little Loca, uma contemporânea de YouTube, debutou em 2006 como uma figura mais equívoca. Uma mexicana-americana do leste de Los Angeles, de 18 anos, Loca mesmerizou as audiências com contos sobre seu irmão superprotetor, suas notas perfeitas e histórias sobre a vida no gueto. Nos primeiros seis meses, ela postou noventa e cinco vídeos e foi vista seis milhões de vezes. ${ }^{28}$ Mas havia mais do que aparecia à primeira vista; Little Loca logo foi lançada como uma atriz batalhadora (e diretora, estrela e operadora de câmera). Stevie Ryan, a atriz que concebeu Loca, misturou o personagem ficcional com aspectos de seu self fora das telas. Enquanto visitava seus pais em Victorville, Califórnia, por exemplo, o carro de Ryan quebrou; ela se transformou em Loca e se voltou para a câmera. Filmando o que ocorreu após o incidente, ela pulou para seu banco dianteiro, voltou a câmera para para CDs e papéis desarrumados e anunciou aos espectadores: "Isso é real, gente. Não estou tentando fazer uma estúpida piada de YouTube ou algo assim...”. Depois de Ryan levar seu cachorro ao veterinário, Loca dedicou parte de um episódio a reclamar sobre os custos das vacinas para cachorro. ${ }^{29}$ Onde as linhas de separação entre Ryan e Loca se confundem na web, o medium também deixa espaço para múltiplas identidades. $\mathrm{Na}$ mesma época em que ela delineou Loca, Ryan estabeleceu outra página apresentando a si mesma como “Jamie Lynn”, uma dura paródia da pop star Britney Spears. Em ainda outra página, ela criou uma persona alternativa, uma estudante francesa de intercâmbio propensa a usar boinas e flertar, cheia de alma, com a câmera.

O ciberespaço foi desenvolvido como um espaço para a troca de ideias e opiniões, mas também proporciona novas oportunidades de auto-expressão, autopromoção, e auto-definição. Identidades parciais emergem, enquanto outras são escondidas. Para obscurecer sua verdadeira identidade (e despistar os repórteres curiosos), Peter Oakley apresentou a si mesmo como um octagenário motociclista que vivia em Leicester, uma cidade afastada de sua isolada cabana no campo. Stevie Ryan apresentou a si mesma como a arrojada Chicana Loca, misturando aspectos de seu self real com os da personagem.
26

Cf. AVGITIDOU, 2003.

27

Para mais sobre esse assunto, cf. LANDOW, George. Hypertext 2.0. Johns Hopkins University Press, 1997; e JOYCE, Michel. Of two minds: hypertext pedagogy and poetics. University of Michigan Press, 1995.

28

McGRATH, Bem. Online chronicles: it should happen to you. The New Yorker, 82, n. 33, oct. 16, p. 86-88, 90-91, 2006.

29

McGRATH, 2006. 
Com o advento do ciberespaço, o self pode existir mais no âmbito digital do que no real. Um guitarrista amador se abstém do sono para olhar solos de si mesmo no YouTube em média 250 vezes por hora; ele conhece seus rankings, mas não tem tempo para praticar a guitarra. ${ }^{30}$ Não apenas a performance cresce em significado, mas as ferramentas digitais que a possibilitam se tornam obrigatórias. Telefones celulares com câmera são carregados não para chamadas, mas para documentar a vida. Quando Stevie Ryan, também conhecida como Little Loca, descobriu que seu carro havia quebrado, foi até a câmera, anunciando, "Sinto que metade da minha vida se foi bem agora. Mas, bom, ao menos, tenho minha câmera, certo? Não levaram minha câmera de vídeo"."1

\section{REFERÊNCIAS}

AVGITIDOU,Angeliki. Performances of the self. Digital Creativity, I 4, n. 3, p. I35-36, 2003.

$B L O O D$, Rebecca (Ed.). We've got blog: how weblogs are changing our culture. New York: Perseus Group Book, 2002.

BRUCKMAN, Amy. Cyberspace is not Disneyland: the role of the artist in a networked world. Getty Art History Information Program, 1995. Disponivel em: <http://www.cc.gatech.edulfac/Amy.Bruckman/papers/ getty/disneyland.html>.

FOUCAULT, Michel. What is an author? In: BOUCHARD, Donald F. (Ed.). Language, counter-memory, practice: selected essays and interviews. Ithaca, NY: Cornell University Press, 1977.

GARRETT, Jesse James. MySpace: design anarchy that works. Business Week Online, january 3, 2006. Disponivel em: <http://www.businessweek.com/innovate/content/dec2005/id2005 I 230_570094.html>. GIBSON, William. Neuromancer. Ace Books, 1984.

GILBERT, Daniel T.; FISKE, Susan T.; LINDZEY, Gardner. The handbook of social psychology. New York: Oxford University Press, 1998.

GREENBLATT, Stephen. Renaissance self-fashioning. Chicago: University of Chicago Press, 1980.

GORE, Albert. Remarks. The superhighway summit, UCLA Royce Hall, january II, 1994. Disponivel em: $<$ http://clinton I.nara.gov/White_House/EOP/OVP/other/superhig.html>.

\section{0}

lbidem.

31

McGRATH, 2006.
JACKSON, Michele H.; PURCELL, Darren. Politics and media richness in WorldWide Web representations of the former Yugoslavia. Geographical Review, 87, n. 2, p. 219 , april 1997.

JOYCE, Michel. Of two minds: hypertext pedagogy and poetics. University of Michigan Press, 1995.

HELLER, Stephen. The new generation gap: an exploratory conversation with John Carlin. Voice: The AIGA Journal of Design, may 22, 2007. Disponivel em: <http://www.aiga.org/content.chm/the-new-generation-gap>. HEMPEL, Jesse; LEHMAN, Paula. The MySpace generation. Business Week Online, december I2, 2005. 
Disponível em: <http://www.businessweek.com/magazine/content/05_50/b396300 I.html>.

LANDOW, George. Hypertext 2.0. Johns Hopkins University Press, 1997.

MARGOLIS, Jonathan. 'Geriatric' Peter, the global web star. Saga Magazine, march I5, 2007. Disponível em: <http://www.saga.co.uk/magazine/people/reallives/geriatric/927_l60307.asp>.

MARSDEN, Joanna Woods. Renaissance self-portraiture: The visual construction of identity and the social status of the artist. Yale University Press, 1998.

McGRATH, Bem. Online chronicles: it should happen to you. The New Yorker, 82, n. 33, oct. 16, p. 86-88, 90-91, 2006.

SELF-STYLING after the "end of art": an interview with Richard Shusterman. Parachute, 105, p. 56-63, spring 2002.

STEWART, Bill. Web browser history: mosaic. Living Internet, 1996-99. Disponível em: <http://www. livinginternet.com/w/wi_browse.html>.

TURKLE, Sherry. Life on the screen: identity in the age of the Internet. Simon \& Schuester, 1995 [1985]. WALLACK, Todd. Curtains in the bedroom - JenniCam switches off. San Francisco Chronicle, december I2, 2003, B4.

WILLIAMS, Alex. Here I am taking my own picture. The New York Times, february 19, 2006, section 9.

\section{MATT FERRANTO}

Professor assistente de Arte no Westchester Community College em Nova York, diretor da Westchester Community College Fine Arts Gallery e editor-chefe de Design and Culture. 
